\title{
Virtual Equivalents of Real Objects (VEROs): A type of non-fungible token (NFT) that can help fund the 3D digitization of natural history collections
}

\author{
SAMUEL J. BOLTON ${ }^{1} \&$ JOSEPH R. CORA ${ }^{2}$ \\ ${ }^{1}$ Florida State Collection of Arthropods, Division of Plant Industry, Florida Department of Agriculture and Consumer Services, \\ Gainesville, FL 32608, USA; !" samuel.bolton77@gmail.com; ‘ https://orcid.org/0000-0002-5807-8519 \\ ${ }^{2} 145$ Clinton Street, No. 5N, New York, NY 10002, USA. ำ https://orcid.org/0000-0002-7143-7555
}

Describing a substantial proportion of the world's species could be made much easier by the 3D digitization of collections, which would facilitate the dissemination of taxonomic information locked up in natural history museums. Three-dimensional imaging captures many characters and allows a lot of versatility in the way that morphological data is displayed and used (Wheeler et al. 2012; Faulwetter et al. 2013). Moreover, the loss and damage of valuable specimens, many of which are very fragile, can be reduced as a result of the use and sharing of $3 \mathrm{D}$ model substitutes among researchers. This can also lead to a reduction in the handling and transportation expenses of many specimens.

The cost of generating 3D models is cheapening due to advances in imaging technology, including new photogrammetric software (Medina et al. 2020; Plum \& Labonte 2021). However, there remain vast logistical and financial challenges to the timely generation of $3 \mathrm{D}$ models of even a small and important proportion of the world's museum specimens, namely all the type specimens and undescribed species. The difficulty of this endeavor is exacerbated by the funding crisis that many natural history collections currently face (Kemp 2015; Miller et al. 2020).

Non-fungible tokens (NFTs), a new type of virtual asset that has gained a lot of media attention in recent months (Clark 2021), could be used to subsidize the costs associated with the large-scale production of 3D models of specimens. NFTs represent unique and irreplaceable digital assets, which are encoded and stored on blockchains in the same basic way as cryptocurrency such as Bitcoin. Some individual NFTs are already being sold for millions of dollars (Blasi 2021; Thaddeus-Johns 2021). NFTs are often used to represent ownership of unique digital objects that do not have real object equivalents, e.g. digital art. But this new technology also allows the tokenized ownership of a 3D model equivalent of a real and unique object. These two entities are interlinked; one represents the real and the other represents the virtual. There can only be one authentic NFT equivalent of any real object. We herein term this type of NFT a Virtual Equivalent of a Real Object (VERO); 'vero' is also an Italian term for 'authentic'.

VEROs can be produced by museums to enable recreational collectors to own NFTs that represent virtual versions of the objects housed within museum collections.
Recreational software applications, including massively multi-user online sites, can be developed or adapted to support VEROs. Because NFTs can be traced back to their origin, traders and collectors can readily authenticate VEROs. Note that buying an NFT does not confer copyright ownership (Bailey 2021). Therefore, although VEROsupported recreational apps can be developed to grant user privileges to the VERO owner, the associated 3D models can be made freely viewable to anyone for research and education. And so VEROs complement rather than compete with the already existing functions of 3D models generated from museum collections.

An object does not have to have a copyright in order to be used to produce and sell an NFT. For example, the Uffizi Gallery in Florence recently sold an NFT representing a Michelangelo painting, which is too old to have a copyright, for $€ 140,000$ (Solomon 2021). But uncopyrighted artworks have also been used to produce NFTs without either ownership of the source object or permission from the owner (Cascone 2021). This makes the production of NFTs a free-for-all, where NFTs of any uncopyrighted cultural item and any biological specimen can be produced and sold by anyone. VEROs must therefore be clearly defined to confer demonstrable value in a meaningful and fair way. Accordingly, we suggest that VEROs are NFTs that meet the following criteria.

- The associated 3D model is as faithful as it can be reasonably expected to be to the real object. But note that a collector could pay to upgrade their VERO when a higher resolution model becomes available through the use of a new or better imaging technology.

- The real object can be unambiguously identified through a unique identifier, e.g. museum barcode or universally unique identifier (UUID).

- The first transaction of the VERO is between the VERO purchaser and the owner of the real object at the time of sale. Any subsequent owners of the real object would be unable to produce and sell their own VERO from it. Therefore, the existence of the VERO should be made known to any prospective buyer of the real object prior to sale.

The real object is trackable and remains demonstrably 
preserved. VEROs cease to exist (are invalidated) when their real object equivalents are destroyed. This firmly anchors the VERO to the real object. Furthermore, the omission of this criterion could lead to the frivolous generation of VEROs from any objects that could then be readily disposed of, which might encourage the generation of VEROs from poached and illegally collected specimens.

Many natural history collections are already being unintentionally primed for the production of VEROs through the use of unique identifiers, which will allow every VERO to be linked to a particular specimen. More and more 3D models are being generated from museum specimens, and so there can be a ready supply of VEROs for use in VERO applications. Museums can then use the proceeds from the sale of VEROs to subsidize the production of more 3D models or the collection of new specimens for 3D model digitization. By offsetting the costs of 3D model production, VEROs can reduce the expenses associated with classifying and describing the world's species. The proceeds from VEROs could also be used to fund under-resourced and vulnerable collections that are in urgent need of public funds.

Because copyright is no more relevant to the sale of VEROs than it is to the sale of real objects such as artworks, VEROs could be traded like bitcoins or regular NFTs among a community of collectors. The use of blockchain technology will mean that VEROs cannot be readily faked. Anyone who chooses to buy one can trace ownership back to the museum source.

There are a number of reasons for collectors of real objects - who make up about a third of North Americans and Europeans (Pearce 1995) - to switch to virtual objects. No storage space or collection equipment is needed to collect VEROs. Also, there are no transportation costs; collectors can trade and display their VEROs from their homes. And VEROs are much more robust than their real-world counterparts as they are digital entities that can be backed up multiple times; they do not require treatment or special storage conditions for preservation. Furthermore, in a virtual environment, objects can be scaled up in size so that fine detail and intricate morphology can be fully appreciated without a magnifying lens or microscope. These many advantages may cause the virtual equivalents of natural history specimens to become more collectable than their real-world counterparts. Real natural history specimens are often very fragile and usually require expensive and specialist equipment to collect and observe in any detail.

The most sought-after natural history VEROs are almost certain to be the virtual equivalents of well-known specimens, such as dinosaur fossils. However, museums are well suited to promote the VEROs of more obscure but rare museum objects, including type specimens, through exhibitions or permanent display space. Museums could also be used to promote the general VERO mission, i.e. the free dissemination of 3D models sourced from public collections. Potential VERO collectors are less likely to cynically assume this is an exploitative venture when they are made aware of the not-for-profit nature of the enterprise. VERO oriented displays could be entertaining and educational for visitors, who could use them to learn more about a museum's collection. And museums could recruit software engineers and developers to develop various VERO oriented apps, including games, which may further appreciate the value of VEROs.

VEROs may also help to promote museum collections by encouraging VERO collectors to learn about the institutions that house and conserve the real-world equivalents of their virtual possessions. For this reason, VEROs might lead to a greater appreciation for the important function that museums have as custodians of our scientific and cultural heritage.

The realization of VEROs will be met with various technical and legal challenges. For example, there will be costs associated with tracking and securing the specimens that are used for generating VEROs. Therefore, it will probably not be financially prudent to generate VEROs for every museum object. And if a specimen that has a VERO is lost or destroyed, the VERO owner would need to be compensated. VEROs could also lead to a reduction of donations to museums from private collectors, who would be less willing to part with specimens when they know their associated VEROs are valuable. Perhaps some agreement could be reached in which the collector donates a specimen and pays for its 3D digitization in exchange for the VERO.

VEROs (or something equivalent) seem likely to become part of the solution to the funding crisis facing many natural history museums. VEROs can offset the costs of $3 \mathrm{D}$ model production, and the greater number of $3 \mathrm{D}$ models should ultimately reduce the costs of travel (when loans are prohibited), shipment and handling associated with specimens. NFTs therefore represent an important new platform through which natural history museums may be able to save money and accumulate much needed funds for the 3D digitization of a significant proportion of their holdings.

\section{Acknowledgement}

Thanks are due to the following individuals for their contribution through internal review and/or useful discussion: Hector Urbina, Elijah Talamas, Paul Skelley (Florida Department of Agriculture and Consumer Services, Gainesville, Florida, USA), Hans Klompen and Norman Johnson (Ohio State University, Columbus, Ohio, USA). We also thank the Florida Department of Agriculture and Consumer Services-Division of Plant Industry for their support on this contribution.

\section{References}

Bailey, J. (2021) NFTs and Copyright. Plagiarism Today. Available from: https://www.plagiarismtoday.com/2021/03/16/nftsand-copyright/ (accessed 22 May 2021)

Blasi, W. (2021) Twitter CEO Jack Dorsey just sold his first tweet as an NFT for \$2.9 million. Marketwatch. Available from: https://www.marketwatch.com/story/twitter-ceo-jackdorsey-just-sold-his-first-tweet-as-an-nft-for-2-9-million11616441795 (accessed 21 May 2021). 
Cascone, S. (2021) A collective made NFTs of masterpieces without telling museums that owned the originals. Was it a digital art heist or fair game? Artnet news. Available from: https:// news.artnet.com/art-world/global-art-museum-nfts-1953404 (accessed 21 May 2021).

Clark, M. (2021) NFTs, explained. The Verge. Available from: https://www.theverge.com/22310188/nft-explainer-what-isblockchain-crypto-art-faq (accessed 20 May 2021).

Faulwetter, S., Vasileiadou, A., Kouratoras, M., Dailianis, T. \& Arvanitidis, C. (2013) Micro-computed tomography: introducing new dimensions to taxonomy. ZooKeys, 263, $1-45$. https://doi.org/10.3897/zookeys.263.4261

Kemp, C. (2015) Museums: The endangered dead. Nature, 518, 292-294. https://doi.org/10.1038/518292a

Medina, J.J., Maley, J.M., Sannapareddy, S., Medina, N.M., Gilman, C.M. \& McCormack, J.E. (2020) A rapid and costeffective pipeline for digitization of museum specimens with 3D photogrammetry. PLoS ONE, 15 (8), e0236417. https://doi.org/10.1371/journal.pone.0236417

Miller, S.E., Barrow, L.N., Ehlman, S.M., Goodheart, J.A., Greiman, S.E., Lutz, H.L., Misiewicz, T.M., Smith, S.M., Tan, M., Thawley, C.J., Cook, J.A. \& Light, J.E. (2020) Building
Natural History Collections for the Twenty-First Century and Beyond. BioScience, 70 (8), 674-687.

https://doi.org/10.1093/biosci/biaa069

Pearce, S.M. (1995) On Collecting: An Investigation into Collecting in the European Tradition. Routledge, London. 448 pp. https://doi.org/10.4324/9780203552209

Plum, F. \& Labonte, D. (2021) scAnt-an open-source platform for the creation of 3D models of arthropods (and other small objects). PeerJ, 9, e11155

https://doi.org/10.7717/peerj.11155

Solomon, T. (2021) In an effort to recoup losses, Uffizi sells renaissance masterpieces as NFTs. ARTnews. Available from: https://www.artnews.com/art-news/news/uffizi-galleriesnfts-caravaggio-botticelli-1234593017/ (accessed 24 May 2021)

Thaddeus-Johns, J. (2021) What are NFTs, anyway? One just sold for $\$ 69$ million. New York Times. Available from: https:// www.nytimes.com/2021/03/11/arts/design/what-is-an-nft. html (accessed 20 May 2021)

Wheeler, Q., Bourgoin, T., Coddington, J., Gostony, T., Hamilton, A., Larimer, R., Polaszek, A., Schauff, M. \& Solis, M.A. (2012) Nomenclatural benchmarking: the roles of digital typification and telemicroscopy. Zookeys, 209, 193-202. https://doi.org/10.3897/zookeys.209.3486 